\title{
Species Composition and Plasmodium falciparum Infection Rates of Anopheles gambiae s.l. Mosquitoes in Six Localities of Kwara State, North Central, Nigeria
}

\section{1*ODUOLA, AO; ${ }^{2}$ OBEMBE, A; ${ }^{1}$ LATEEF, SA; ${ }^{1}$ ABDULBAKI, MK; ${ }^{1}$ KEHINDE, EA; ${ }^{1}$ ADELAJA, OJ; ${ }^{1}$ SHITTU, O; ${ }^{3}$ TOLA, M; ${ }^{3}$ OYENIYI, TA; ${ }^{3}$ AWOLOLA, TS}

\author{
${ }^{* 1}$ Department of Zoology, University of Ilorin, Ilorin, Kwara State, Nigeria \\ ${ }^{2}$ Department of Biosciences and Biotechnology, Kwara State University, Malete, Nigeria \\ ${ }^{3}$ Molecular Entomology and Vector Control Research Laboratory, Nigerian Institute of Medical Research, Yaba, Lagos, Nigeria \\ *Corresponding Author's Email: dayooduola@yahoo.co.uk,Tel: +2348053327203
}

\begin{abstract}
Entomological data gathering is essential for monitoring malaria vector disease risks and selection of appropriate interventions for the protection of exposed human populations. This study assessed the relative abundance, species composition, and sporozoite infection rates of indoor resting An. gambiae s.l. malaria vectors in six communities across 3 Local Government Areas in Kwara State, Nigeria. Total number of mosquitoes collected by Pyrethrum Spray Catch method over a period of eighth months were correlated with rainfall values in the area. Plasmodium falciparum sporozoite infection rates and sibling species identification of collected An. gambiae s.l. mosquito samples were determined by ELISA and PCR respectively. Results showed a positive correlation $(r=0.639, p=0.08)$ between rainfall and numbers of Anopheles mosquitoes in the study areas. The overall composition of the An. gambiae s.l sibling species in the collected samples from all the six communities showed the predominance of An. gambiae s.s 298 (75.3\%) compared to An. coluzzii 94(23.7\%) and An. arabiensis 4(1.0\%). However, the sporozoite infection rate of An. coluzzii (22.3\%) was higher compared to An. gambiae s.s (12.8\%) and An. arabiensis (0\%). Mean numbers of An. gambiae s.l mosquitoes were significantly higher in Ilorin west LGA compared to Asa $(\mathrm{F}=17.81, \mathrm{P}<0.001)$ and Ilorin East LGAs $(\mathrm{F}=22.81, \mathrm{P}<$ 0.001). Sporozoite rates of both An. gambiae s.s and An. coluzzii sibling species were higher in Ilorin West communities (Aiyede 21\%, Ogundele 32\%) compared to Asa (Idi Emi 11.1\%, Lasoju 5.1\%) and Ilorin East (Oke Oyi 2.4\%, Ote-efan $0 \%)$ communities. Prevalence of sporozoite-infected An. gambiae s.s and An. coluzzii indoors highlight the need for effective insecticide treated bed-nets interventions to protect the residents from malaria risks. Higher numbers of $A n$. coluzzii in the swampy rice marshed Ilorin West LGA communities require larval source management as an additional strategy for effective malaria vector control.
\end{abstract}

\section{DOI:https://dx.doi.org/10.4314/jasem.v25i10.8}

Copyright: Copyright (c) 2021 Oduola et al. This is an open access article distributed under the Creative Commons Attribution License (CCL), which permits unrestricted use, distribution, and reproduction in any medium, provided the original work is properly cited.

Dates: Received: 22 August 2021; Revised: 17 September 2021; Accepted: 06 October 2021

Keywords: Anopheles mosquitoes, sibling species composition, Plasmodium falciparum, malaria

The Nigeria National Malaria Strategic Plan (NMSP) 2014-2020 (FMoH, 2014) listed vector control as the first objective for reducing malaria burden. The NMSP aimed at ensuring that $80 \%$ of Nigerians utilize preventive measures by the year 2020. As such vector control remains the frontline means of preventing and reducing malaria transmission (WHO, 2018). Implementation of cost-effective vector control interventions rely on adequate knowledge of local vector species attained through sustained entomological monitoring and surveillance activities (WHO, 2019). Such surveillance activities provide information on the dynamics of vector species composition, relative abundance, and sporozoite infection rates (Mbogo et al., 2003). Besides, these and other entomological indices such as vector behaviour and insecticide susceptibility status also serve as the basis for measuring the impact of vector control strategies on malaria transmission (WHO,
2019). Significant spatial heterogeneities have been observed in the abundance of indoor resting Anopheles mosquitoes, their species composition and sporozoite infection rates (Sinka et al., 2011). Characterization of entomological indices and mosquito behaviour in different settings, therefore, becomes necessary to guide the suitability of interventions such as LongLasting Insecticide Nets (LLINs) and Indoor Residual Spray (IRS) designed to target indoor biting or resting mosquitoes (Conn et al., 2015). In Nigeria, the involvement of government and non - governmental partners in vector surveillance and insecticide resistance monitoring implementation has increased across the six geo-political zones (PMI-AIRS, 2018), thus providing comprehensive entomological data for the replacement of isolated entomological surveys of limited scope in Nigeria. Outcomes of these routine monitoring have provided data on malaria vector prevalence and infectivity rates in Nigeria. 
Nevertheless, there is still a paucity of data in some states such as Kwara. This leaves a huge gap to be filled for proper planning, implementation and monitoring of the impact of interventions in reducing human-vector contact in different settings within Kwara and other states in the country where capacity for vector surveillance and insecticide resistance monitoring have not been built. This study provides information on the relative abundance, species composition and Plasmodium falciparum sporozoite infection rates of Anopheles mosquitoes in six communities across three selected Local Government Areas of Kwara State, North Central Nigeria.

\section{MATERIALS AND METHODS}

Description of Study area: The study was carried out in six rural communities: Lasoju (N 8 ${ }^{\circ} 21.856^{\prime} \mathrm{E}$ $\left.4^{\circ} 26.201^{\prime}\right)$, Idi -Emi (N 8²1.889' E $\left.4^{\circ} 26.491 '\right)$, Oke - Oyi (N 8³5' 38.8' E 443' 30.0'), Ote-efan (N 8³4' $25.0^{\prime}$ E $\left.4^{\circ} 42^{\prime} 18.8^{\prime}\right)$, Ogundele ( $8^{\circ} 29.384^{\prime}$ E $4^{\circ}$ 26.868') and Aiyede ( $8^{\circ} 29.442^{\prime}$ E $\left.4^{\circ} 27.374^{\prime}\right)$. The communities are located in Asa (Lasoju and Idi-Emi), Ilorin East (Oke - Oyi and Ote-efan) and Ilorin West (Ogundele and Aiyede) LGAs in Kwara State, NorthCentral, Nigeria. Kwara state is within the transitional climate zone. The rainy season begins from the end of March and ends in October with two peak periods in June and September while the dry season starts in October and ends in February. The annual mean rainfall is about $1,352 \mathrm{~mm}$ (Alaaya et al., 2013). Houses in all the study communities were built with mud and corrugated metal sheet, with no ceilings and window nets. The inhabitants are mostly farmers.

Mosquito sample and data collection: Indoor resting mosquitoes were collected in ten houses per community from September 2017 to April 2018 using Pyrethrum spray catch techniques (WHO, 2003). Houses with household heads willing to allow monthly long-term mosquito surveys in the sleeping rooms were chosen until ten houses were randomly selected. One room was surveyed in each house. The same rooms and houses were used for mosquito collections all through the period of the study. Rainfall data for the State was obtained from the Nigerian Meteorological Station at the Ilorin International Airport during the period of the study

Treatment and Analysis of Sample: Mosquitoes collected were preserved individually in Eppendorf tubes with desiccated silica gel. Morphological identification of collected Anopheles mosquitoes was conducted using standard keys (Gillies and De Meillon, 1968; Gillies and Coetzee, 1987). Mosquitoes identified as Anopheles gambiae s.l were subjected to PCR assays for sibling species identification using the method of Scott et al. (1993) and Favia et al. (1997). Presence of Plasmodium falciparum circumsporozoite protein (CSP) in the heads-thoraces of all the Anopheles gambiae s.l. mosquitoes collected was determined by the circumsporozoite ELISA as described by Wirtz et al. (1987). Positive controls and monoclonal antibodies used for the sporozoite ELISA were supplied by Centers for Disease Control and Prevention (CDC) in Atlanta USA. Non-blood-fed laboratory-reared $A n$. gambiae Kisumu susceptible strain mosquitoes were used as negative controls. Unfed mosquitoes (4 in Oke-Oyi and 1 in Ote-efan) collected during the study were excluded from the ELISA analysis.

Statistical Evaluation of Data: Numbers of mosquitoes and rainfall values were transformed $(\sqrt{ } \mathrm{n}+0.5)$ to accommodate zero values and attain normal distribution. Monthly numbers of mosquitoes collected from all the six communities were pooled and correlated (Pearson's correlation) with monthly rainfall for the state during the study period. Numbers of the An. gambiae s.l mosquitoes collected were compared across the six communities and 3 LGAs using ANOVA at $\mathrm{P}<0.05$ (SPSS statistical software version 20). Sporozoite rate was determined as numbers of mosquitoes that tested positive for $P$. falciparum sporozoites divided by the total numbers of a particular sibling species tested for sporozoites multiplied by 100 .

\section{RESULTS AND DISCUSSION}

A total of 1,018 samples comprising Anopheles 864 (84.9\%), Aedes 104 (10.2\%) and Culex 50 (4.9\%) mosquitoes were collected. In Oke - Oyi, higher proportions of Aedes spp. 69 (46.3\%) mosquitoes were found indoors compared to all other sites. However, Anopheles gambiae s.l. was the predominant mosquito species $(49.7 \%-95.8 \%)$ across all the communities (Table 1). Though this is not the focus of this study, the close interaction of culicine mosquito vectors of filariasis and yellow fever among the residents of these three LGAs may imply increase risk of the residents to other mosquito-borne diseases apart from malaria. Sympatric occurrence of fewer numbers of indoor resting culicine mosquitoes relative to predominant Anopheles mosquitoes (85\%) has been reported in rural communities located in both southwest and north-central regions of Nigeria (Oduola et al., 2013; 2016). The number of Anopheles gambiae s.l mosquitoes in October was higher compared to all other months (Table 2). Correlation between rainfall and pooled monthly numbers of Anopheles mosquitoes in all the communities was moderate and positive but not significant $(\mathrm{r}=0.639, \mathrm{p}=0.08)$ (Table $2)$. The highest rainfall value $(510.8 \mathrm{~mm})$ was recorded 
in September. This could have been responsible for the higher numbers of Anopheles gambiae s.l mosquitoes collected during the following month of October compared to other months. Mean numbers of $A n$. gambiae s.1. mosquitoes in the two communities within each LGA were not significantly different from each other; Idi-Emi and Lasoju in Asa LGA $(\mathrm{F}=0.75$, $\mathrm{P}=0.980$ ), Oke-oyi and Otefan in Ilorin East LGA $(\mathrm{F}=0.25, \mathrm{P}=0.945)$, Aiyede and Ogundele in Ilorin West LGA $(\mathrm{F}=0.13$; $\mathrm{P}=0.993)$ (Table 3). These results showing no significant differences in the mean numbers of female An. gambiae s.l. mosquitoes between the two communities within the same LGA suggest that similar Anopheles mosquito resting behaviour existed within the communities in each LGA. Pooled mean number of An. gambiae s.l. mosquitoes was significantly higher in Ilorin West LGA (7.56 \pm 2.66$)$ compared to Asa $(4.64 \pm 2.6$; F = 17.81, $\mathrm{P}<0.001)$ and Ilorin East $(3.00 \pm 3.16 ; \mathrm{F}=$ 22.81, P < 0.001) LGAs (Table 4). Out of the 396 An. gambiae s.l. subjected to PCR analysis, three sibling species comprising Anopheles gambiae s.s 298 (75.3\%), Anopheles coluzzii 94 (23.7\%) and Anopheles arabiensis 4(1.0\%) were identified (Table 5). An. gambiae s.s was predominant over An. coluzzii and $A n$. arabiensis in all the communities and LGAs. Fewer numbers of An. arabiensis were found only in Idi Emi and Lasoju communities in Asa LGA (Table 5). Both An. gambiae s.s and An. coluzzii vector species carried the $P$. falciparum sporozoites. The infection rate in An. gambiae s.s and An. coluzzii across all the 6 communities ranged between $2.4 \%$ $30 \%$ and $6.7 \%-36 \%$ respectively (Table 6 .). The sporozoite infection rate of An. gambiae s.s (12.8\%) across the communities was lower compared to that of An. coluzzii (22.3\%). Overall, the sporozoite rate of An. gambiae s.l. was higher in Ilorin -West (Aiyede $21.1 \%$, Ogundele, $32.0 \%$ ) compared to Asa (Idi-Emi $11.1 \%$; Lasoju, 5.5\%) and Ilorin East (Oke Oyi, 2.4\%; Ote-efan $0 \%$ ) communities.

Higher numbers of female An. gambiae s.l. and increased $P$. falciparum sporozoite infection in the mosquitoes in the two communities in Ilorin West LGA, where there are available paddy rice farming areas for larval breeding, suggest increased exposure of humans to infected mosquitoes. Houses located around breeding sites have been reported to contribute significantly to increased abundance of indoor resting adult malaria vector species in Kenya (McCan et al., 2017). In Ethiopia, Kibret et al. (2014) also reported significantly higher Plasmodium falciparum sporozoites rates and vector densities in Anopheles arabiensis and Anopheles pharoensis in irrigated villages compared to non-irrigated villages. Results found here are predictive indicators to ensuring increased access and use of LLIN among the residents in these communities. An. gambiae s.s was more abundant than An. coluzzii in the pooled samples from all the communities in Ilorin. This is in agreement with the overall composition from other surveillance sites in Nasarawa, Oyo and Plateau state sharing the same guinea savannah ecological zone with Kwara state (PMI-AIRS, 2018). The preponderance of $A n$. gambiae s.s over An. coluzzii in Asa and Ilorin East LGAs is in contrast with Ilorin West LGA communities where a higher proportion of An. coluzzii mosquitoes were observed (Aiyede 43\%; Ogundele $33 \%)$. This can be attributed to the presence of perennial paddy rice farms serving as the preferential mosquito larvae breeding sites in the Ilorin West LGA study communities. An. coluzzii larvae have previously been reported to utilize relatively permanent water bodies which are abundant in both urban and peri-urban Lagos in the forest ecological zone (Oduola et al., 2012). Similar predominance of An. coluzzii have also been reported in Auyo (Kano State) and Rabah, Sentinel site (Sokoto State) (Ibrahim et al., 2014; PMI, 2018) in the Sudan savannah ecological zone of Northern Nigeria. Also, An. coluzzii was reported predominantly in Ebonyi, located in forest ecological zone in South Eastern, Nigeria (PMI, 2018). All of these sites showing preponderance of An. coluzzii are associated with the historical practice of irrigation activities supporting vegetable and paddy rice farming systems. Occurrence of these favourable relatively permanent water bodies for An. coluzzii mosquito larval breeding may have influenced and supported the varying predominant patterns of $A n$. coluzzii distribution observed along the various ecological zones. Anopheles arabiensis species were not encountered in most of the communities in this study probably because of the absence of suitable animal hosts to support its zoophilic tendencies and exophilic preferences (Massebo et al., 2015). Higher proportion of An. arabiensis mosquito sibling species $(65 \%)$ have been reported in Gaa - Bolorunduro, another community in Kwara state with heavy presence of Fulani Cattle herders and their animals (Oduola et al., 2016). The negligible occurrence of $A n$. arabiensis sibling species in the present study is in consonance with $0.6 \%$ An. arabiensis incidence recorded in two other non-cattle rearing communities in Kwara State (Obembe et al., 2018). To our knowledge, this is a first report on the role of Anopheles coluzzii and An. gambiae s.s as vectors involved in malaria transmission in Kwara State, North Central Nigeria. Previous studies by Oduola et al., (2016) only identified An. gambiae s.s, An. coluzzii and An. arabiensis in Ilorin East and Ilorin South LGAs but was unable to determine their infectivity rates. 
Species Composition and Plasmodium falciparum Infection Rates.....

Table 1: Number of female mosquito species collected from the rural Communities.

\begin{tabular}{|c|c|c|c|c|c|}
\hline \multirow[b]{2}{*}{ LGA } & \multirow[b]{2}{*}{ Community } & \multicolumn{3}{|c|}{ Mosquito composition N (\%) } & \multirow[t]{2}{*}{ Total } \\
\hline & & Anopheles spp. & Culex spp. & Aedes spp. & \\
\hline \multicolumn{6}{|l|}{ Asa } \\
\hline & Idi-Emi & $112(82.4)$ & $8(5.9)$ & $16(11.8)$ & 136 \\
\hline & Lasoju & $106(89.0)$ & $9(7.6)$ & $4(3.4)$ & 119 \\
\hline \multicolumn{6}{|c|}{ Ilorin East } \\
\hline & Oke-Oyi & 74(49.7) & $6(4)$ & $69(46.3)$ & 149 \\
\hline & Ote-efan & $69(77.5)$ & $10(11.2)$ & $10(11.2)$ & 89 \\
\hline \multicolumn{6}{|c|}{ Ilorin-West } \\
\hline & Aiyede & $251(95.8)$ & $8(3.1)$ & $3(1.1)$ & 262 \\
\hline & Ogundele & $252(95.8)$ & $9(3.4)$ & $2(0.8)$ & 263 \\
\hline Total & & $864(84.9)$ & $50(4.9)$ & $104(10.2)$ & 1018 \\
\hline
\end{tabular}

Table 2: Correlation of total numbers of female An. gambiae s.l. mosquitoes with rainfall values

\begin{tabular}{llllllllll}
\hline \multirow{2}{*}{ Month } & Asa & \multicolumn{9}{c}{ Ilorin East } & \multicolumn{2}{c}{ Ilorin West } & \multirow{2}{*}{ ATM-M } & \multirow{2}{*}{ ATM-R } & Correlation \\
\cline { 2 - 6 } \cline { 3 - 7 } & IE & La & OO & OF & Ai & Og & & \\
\hline Sept & 21 & 23 & 5 & 2 & 26 & 27 & $104(10.22)$ & $510.8(22.6)$ & $\mathrm{r}=0.639$ \\
Oct & 42 & 54 & 51 & 63 & 82 & 57 & $349(18.69)$ & $367.9(19.2)$ & \\
Nov & 10 & 8 & 3 & 2 & 52 & 19 & $94(9.72)$ & $26.9(5.23)$ & $\mathrm{P}=0.087$ \\
Dec & 6 & 5 & 5 & 0 & 6 & 11 & $33(5.79)$ & $10(3.24)$ & \\
Jan & 1 & 0 & 0 & 1 & 1 & 11 & $14(3.81)$ & $1.9(1.55)$ & \\
Feb & 10 & 1 & 2 & 0 & 31 & 38 & $82(9.08)$ & $1.33(1.35)$ & \\
Mar & 5 & 3 & 1 & 0 & 19 & 40 & $68(8.28)$ & $1.24(1.32)$ & \\
Apr & 17 & 12 & 3 & 0 & 34 & 49 & $115(10.75)$ & $2.8(1.82)$ & \\
\hline
\end{tabular}

Where ATM- $M$ = Actual (Transformed) Monthly total Numbers of mosquitoes; ATM- $R=$ Actual (Transformed) Monthly total Rainfall values $(\mathrm{mm}) ; \mathrm{IE}=$ idi-Emi; $\mathrm{La}=\mathrm{Lasoju} ; \mathrm{OO}=$ Oyeke-Oyi; OF = Ote-Fan; Ai = Aiyede; Og = Oygyundele; $P$ and $r$ values are from correlations of transformed monthly total numbers of mosquitoes and transformed rainfall values

Table 3: Comparisons of mean numbers of An. gambiae s.l collected from the six communities.

\begin{tabular}{|c|c|c|c|c|c|c|c|c|c|}
\hline Month & Asa & & & Ilorin East & & & Ilorin West & & \\
\hline & IE & $\mathrm{La}$ & $\mathrm{P}$ value & $\mathrm{OO}$ & $\mathrm{OF}$ & $P$ value & $\mathrm{Ai}$ & $\mathrm{Og}$ & \\
\hline & ATN & ATN & & ATMN & ATMN & & ATMN & ATMN & value \\
\hline Sept & $21(4.64)$ & $23(4.85)$ & \multirow{8}{*}{0.980} & $5(2.35)$ & $2(1.58)$ & & $26(5.15)$ & $27(5.24)$ & \multirow{8}{*}{0.993} \\
\hline Oct & $42(6.52)$ & $54(7.38)$ & & $51(7.18)$ & $63(7.97)$ & & $82(9.08)$ & $57(7.58)$ & \\
\hline Nov & $10(3.24)$ & $8(2.92)$ & & $3(1.87)$ & $2(1.58)$ & & $52(7.25)$ & $19(4.42)$ & \\
\hline Dec & $6(2.55)$ & $5(2.35)$ & & $5(2.35)$ & $0(0.71)$ & & $6(2.55)$ & 11(3.39) & \\
\hline Jan & $1(1.22)$ & $0(0.71)$ & & $0(0.71)$ & $1(1.22)$ & 0.945 & $1(1.22)$ & 11(3.39) & \\
\hline Feb & $10(3.24)$ & $1(1.22)$ & & $2(1.58)$ & $0(0.71)$ & & $31(5.61)$ & $38(6.20)$ & \\
\hline Mar & $5(2.35)$ & $3(1.87)$ & & $1(1.22)$ & $0(0.71)$ & & $19(4.42)$ & $40(6.36)$ & \\
\hline Apr & $17(4.18)$ & $12(3.54)$ & & $3(1.87)$ & $0(0.71)$ & & $34(5.87)$ & $49(7.04)$ & \\
\hline $\begin{array}{l}\text { Mean } \\
\text { number } \\
\pm \text { S.D }\end{array}$ & $3.49 \pm 1.62^{\mathrm{ab}}$ & $3.11 \pm 2.17^{\mathrm{a}}$ & & $2.39 \pm 2.01^{\mathrm{a}}$ & $1.90 \pm 2.48^{\mathrm{a}}$ & & $5.14 \pm 2.49^{b c}$ & $5.45 \pm 1.61^{\mathrm{c}}$ & \\
\hline
\end{tabular}
0.05.; ATMN = Actual (Transformed) no

Table 4: Comparisons of mean numbers of female Anopheles mosquitoes across the three LGAs

\begin{tabular}{|c|c|c|c|c|c|c|c|c|c|}
\hline \multirow[t]{3}{*}{ Month } & \multicolumn{3}{|c|}{ Asa } & \multicolumn{3}{|c|}{ Ilorin East } & \multicolumn{3}{|c|}{ Ilorin West } \\
\hline & IE & La & TAT & OO & OF & TAT & $\mathbf{A i}$ & $\mathbf{O g}$ & TAT \\
\hline & $\mathbf{A}$ & $\mathbf{A}$ & & $\mathbf{A}$ & $\mathbf{A}$ & & $\mathbf{A}$ & A & Med \\
\hline Sept & 21 & 23 & $44(6.67)$ & 5 & 2 & $7(2.74)$ & 26 & 27 & $53(7.31)$ \\
\hline Oct & 42 & 54 & $96(9.82)$ & 51 & 63 & $114(10.70)$ & 82 & 57 & $139(11.81)$ \\
\hline Nov & 10 & 8 & $18(4.30)$ & 3 & 2 & $5(2.35)$ & 52 & 19 & $71(8.46)$ \\
\hline Dec & 6 & 5 & 11(3.39) & 5 & 0 & $5(2.35)$ & 6 & 11 & $17(4.18)$ \\
\hline Jan & 1 & 0 & $1(1.22)$ & 0 & 1 & $1(1.22)$ & 1 & 11 & $12(3.54)$ \\
\hline Feb & 10 & 1 & $11(3.39)$ & 2 & 0 & $2(1.58)$ & 31 & 38 & $69(8.34)$ \\
\hline Mar & 5 & 3 & $8(2.92)$ & 1 & 0 & $1(1.22)$ & 19 & 40 & $59(7.71)$ \\
\hline Apr & 17 & 12 & $29(5.43)$ & 3 & 0 & $3(1.87)$ & 34 & 49 & $83(9.14)$ \\
\hline
\end{tabular}

\pm S.D

$\overline{\text { Mean values having the same letter superscript along the same row are not significantly different at } P<0.05 . I E A=I d i-E m i}$ Actual no; La A= Lasoju Actual no; TAT = Total Actual (Transformed) no; OO A=Oke-oyi; OF A = Ote-fan Actual no; Actual no; TAT = Total Actual (Transformed) no; Ai A = Aiyede Actual no; Og A = Ogundele Actual no; TAT med = Total Actual (Transformed) no

ODUOLA, AO; OBEMBE, A; LATEEF, SA; ABDULBAKI, MK; KEHINDE, EA; ADELAJA, OJ; SHITTU, O; TOLA, M; OYENIYI, TA; AWOLOLA, TS 
Table 5: Sibling species composition of An. gambiae s.l. collected from the communities.

\begin{tabular}{llllll}
\hline LGA & Villages & $\mathbf{N}$ & $\begin{array}{l}\text { An. gambiae } \\
\mathbf{n}(9)\end{array}$ & $\begin{array}{l}\text { An. coluzzii } \\
\mathbf{n}(9)\end{array}$ & $\begin{array}{l}\text { An. arabiensis } \\
\mathbf{n}(\%)\end{array}$ \\
\hline Asa & Idi-Emi & 63 & $46(73.0)$ & $15(23.8)$ & $2(3.2)$ \\
& Lasoju & 55 & $51(92.8)$ & $2(3.6)$ & $2(3.6)$ \\
\multirow{4}{*}{ Ilorin East } & Total & 118 & $\mathbf{9 7}(82.2)$ & $\mathbf{1 7}(14.4)$ & $\mathbf{4 ( 3 . 4 )}$ \\
& Oke-Oyi & 42 & $41(97.6)$ & $1(2.4)$ & 0.0 \\
& Ote-efan & 47 & $45(95.7)$ & $2(4.3)$ & 0.0 \\
Ilorin West & Total & $\mathbf{8 9}$ & $\mathbf{8 6 ( 9 6 . 6 )}$ & $\mathbf{3 ( 3 . 4 )}$ & $\mathbf{0 . 0}$ \\
& Aiyede & 114 & $65(57.0)$ & $49(43.0)$ & 0.0 \\
& Ogundele & 75 & $50(66.7)$ & $25(33.3)$ & 0.0 \\
Grand total & Total & $\mathbf{1 8 9}$ & $\mathbf{1 1 5}(60.8)$ & $\mathbf{7 4 ( 3 9 . 2 )}$ & $\mathbf{0 . 0}$ \\
\hline
\end{tabular}

$N=$ Number of mosquitoes analyzed, $n=$ numbers identified by $P C R$

Table 6. Plasmodium falciparum infection rates of An. gambiae sibling species in the communities

\begin{tabular}{|c|c|c|c|c|c|c|c|c|c|}
\hline \multirow[b]{2}{*}{ LGA } & \multirow[b]{2}{*}{ SC } & \multirow[b]{2}{*}{ NBF } & \multicolumn{2}{|c|}{ An. gambiae } & \multicolumn{2}{|c|}{ An. coluzzii } & \multicolumn{2}{|c|}{ An. arabiensis } & \multirow[b]{2}{*}{ Overall } \\
\hline & & & $\begin{array}{l}\text { PCR } \\
\text { identified }\end{array}$ & $\begin{array}{l}\text { No +ve } \\
\text { for CSP } \\
\text { N (SR) }\end{array}$ & $\begin{array}{l}\text { PCR } \\
\text { identified }\end{array}$ & $\begin{array}{l}\text { No +ve } \\
\text { for CSP } \\
\text { N (SR) }\end{array}$ & $\begin{array}{l}\text { PCR } \\
\text { identified }\end{array}$ & $\begin{array}{l}\text { No +ve } \\
\text { for CSP } \\
\text { N (SR) }\end{array}$ & \\
\hline \multirow[t]{2}{*}{ Asa } & Idi-Emi & 112 & 46 & $6(13.0)$ & 15 & $1(6.7)$ & 2 & $0(0)$ & 11.1 \\
\hline & Lasoju & 106 & 51 & $3(5.9)$ & 2 & $0(0)$ & 2 & $0(0)$ & 5.5 \\
\hline Ilorin & Oke-Oyi & 70 & 41 & $1(2.4)$ & 1 & $0(0)$ & 0 & $0(0)$ & 2.4 \\
\hline East & Ote-efan & 68 & 45 & $0(0)$ & 2 & $0(0)$ & 0 & $0(0)$ & 0.0 \\
\hline Ilorin & Aiyede & 251 & 65 & $13(20)$ & 49 & $11(22.4)$ & 0 & $0(0)$ & 21.1 \\
\hline \multirow[t]{2}{*}{ West } & Ogundele & 252 & 50 & $15(30)$ & 25 & $9(36)$ & 0 & $0(0)$ & 32.0 \\
\hline & Total & 859 & 298 & $38(12.8)$ & 94 & 21(22.3) & 4 & $\mathbf{0}(\mathbf{0})$ & 15.1 \\
\hline
\end{tabular}

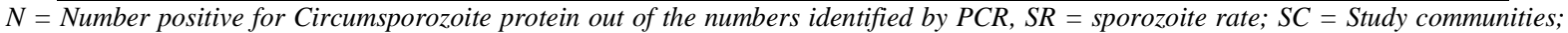
$N B F=N o$ of blood-fed and half-gravid An. gambiae s.l; Overall = Overall An. gambiae s.l Sporozoite infection rates

Significant association was previously observed between the occurrence of An. gambiae s.s and An. coluzzii and a high incidence of reported malaria cases in Ilorin - East LGA (Oduola et al., 2016). Strong indoor presence of two confirmed vectors of malaria validates the need for increased access of communities in Kwara state to protective interventions such as indoor residual spray or insecticide-treated nets. This will protect residents in the communities from hostseeking Plasmodium falciparum-infected mosquitoes. Likewise, selective larviciding will be appropriate to reduce the density of Anopheles gambiae s.l. mosquitoes observed in the Ilorin- West LGA communities.

Conclusion: This study presents a first report on the role of An. coluzzii and An. gambiae s.s mosquito sibling species as vectors involved in malaria transmission in Kwara State, North Central Nigeria. Endophilic nature of the highly infected An. coluzzii and An. gambiae s.s mosquito collected indoors in the study areas suggests the need for effective use of indoor malaria vector control interventions such as insecticide treated bed-nets for the prevention of malaria morbidity and mortality in the localities.

Acknowledgements: The officials of Kwara State Roll Back Malaria Office are gratefully acknowledged for their support during the social advocacy visits to the communities. This work received partial support under the Multilateral Initiative on Malaria (MIM) project
B40411 awarded to AOO through the UNICEF/UNDP/World Bank/WHO Special Programme for Research and Training in Tropical Diseases (TDR).

\section{REFERENCES}

Alaaya, BA; Adetimirin, OI; Alagbe, AO (2013). Investigation of ground water reservoir in Asa and Ilorin west local government of Kwara State using geographic information system. FIG Working Week 2013 Environment for Sustainability Abuja, Nigeria, 6 - 10 May 2013.

Conn, JE; Norris, DE; Donnelly, MJ; Beebe, NW; Burkot, TR; Brahi, M; Chery, L; Eapen, A; Keven, JB; Kilama, M; Kumar, A; Lindsay, S; Moreno, M; Quinones, M; Reimer, L; Russell, TL; Smith, DL; Thomas, MB; Walker, E; Wilson, ML; Yan G (2015). Entomological Monitoring and Evaluation: Diverse Transmission Settings of ICEMR Projects Will Require Local and Regional Malaria Elimination Strategies. Am J Trop Med Hyg 93: 2841.

Favia, G; della Torre, A; Bagayoko, M; Lanfrancotti, A; Sagnon, N; Toure, YT; Coluzzi, M (1997). Molecular identification of sympatric chromosomal forms of Anopheles gambiae and further evidence of their reproductive isolation. Ins Mol Biol 6: 377-383. 
Species Composition and Plasmodium falciparum Infection Rates.....

FMOH (2014). National Malaria Elimination Programme: National Malaria Strategic Plan 20142020, Nigeria. 2014.

Gillies, M. T. \& Coetzee, M. A. (1987). Supplement to the Anophelinae of Africa South of the Sahara (Afrotropical region). Pub South Afr Inst Med Res 55: 141-143.

Gillies, M; De Meillon, B (1968). The Anophelinae of Africa South of the Sahara (Ethiopian zoogeographical region). Pub South Afr Inst Med Res 54: 343.

Ibrahim, SS; Yayo, AM; Tukur, Z; Irving, H; Wondji, CS (2014). High frequency of $k d r \mathrm{~L} 1014 \mathrm{~F}$ is associated with pyrethroid resistance in Anopheles coluzzii in Sudan savannah of northern Nigeria. BMC Infect Dis 14: 441

Kibret, S; Wilson, GG; Tekie, H; Petros, B (2014). Increased malaria transmission around irrigation schemes in Ethiopia and the potential of canal water management for malaria vector control. Malar $J$ $13: 360$.

Massebo, F; Balkew, M; Gebre-Michael, T; Lindtjørn, B (2015). Zoophagic behaviour of anopheline mosquitoes in southwest Ethiopia: opportunity for malaria vector control. Parasit Vector 8: 645.

Mbogo, CM; Mwangangi, JM; Nzovu, J; Gu, W; Yan, G; Gunter, JT; Swalm, C; Keating, J; Regens, JL; Shililu, JI; Githure, JI; Beier, JC (2003). Spatial and temporal heterogeneity of Anopheles mosquitoes and Plasmodium falciparum transmission along the Kenyan coast. Am J Trop Med Hyg 68: 734-742

McCann, RS; Messina, JP; MacFarlane, DW; Bayoh, MN; Gimnig, JE; Giorgi, E; Walker, ED (2017). Explaining variation in adult Anopheles indoor resting abundance: the relative effects of larval habitat proximity and insecticide-treated bed net use. Malar J 17: 288.

Obembe, A; Popoola, KOK; Oduola, AO; Awolola, ST (2018). Mind the weather: a report on inter-annual variations in entomological data within a rural community under insecticide-treated wall lining installation in Kwara State, Nigeria. Parasit Vectors 11: 497.

Oduola, AO; Adelaja, OJ; Aiyegbusi, ZO; Tola, M; Obembe, A; Ande, AT; Awolola, S (2016). Dynamics of Anopheline vector species composition and reported malaria cases during the rain and dry season in two selected communities in Kwara state. Nig J Parasitol 37: 158-164
Oduola, AO; Idowu, ET; Oyebola, MK; Adeogun, AO; Olojede, JB; Otubanjo, OA (2012). Evidence of carbamate resistance in urban populations of Anopheles gambiae s.s. mosquitoes resistant to DDT and deltamethrin insecticides in Lagos, SouthWestern Nigeria. Parasit Vectors 5:116.

Oduola, AO; Obembe, A; Adelaja, OJ; Ande, AT (2016). Surveillance and insecticide susceptibility status of culicine mosquitoes in selected communities utilizing long-lasting insecticidal nets in Kwara State, Nigeria. Animal Res Intl 13 (3):2483-91.

Oduola, AO; Obembe, A; Adeogun, AO; Awolola, TS (2013). Entomological and transmission risk indices of malaria vectors in selected communities in Osun State, Nigeria. Animal Res Intl 10 (3):1805-8.

PMI-AIRS (2017). Nigeria Final Entomology Report. January - December. Rockville, Maryland, USA: Africa Indoor Residual Spraying Project, 2018. Abt Associates Inc. Contract.

Scott, JA; Brogdon, WG; Collins, FH (1993). Identification of single specimens of the Anopheles gambiae complex by the polymerase chain reaction. Am J Trop Med Hyg 49: 520-529

Sinka, ME; Bangs, MJ; Manguin, S; Chareonviriyaphap, T; Patil, AP; Temperly, WH; Gething, PW; Elyazar, IRF; Kabaria, CW; Harbach, RE; Hay, SI (2011). The dominant Anopheles vectors of human malaria in the Asia-Pacific region: occurrence data, distribution maps and bionomic précis. Parasit Vectors 4: 89.

WHO (2003). Malaria entomology and vector control: Learner's guide. World Health Organization. Geneva. http://whqlibdoc.who.int/hq/2003/WHO_CDS_CPE_SMT_2002.18_Rev.1_PartI.pdf

WHO (2018). Fact sheet: World Malaria Report 2018. Available at www.who.int/malaria/media/worldmalaria-report-2018/en/ Accessed November 1, 2019

Wirtz, RA; Zavala, F; Charoenvit, Y; Cambell, GH; Burkot, TR; Schneider, I; Esser, KM; Beaudoin, RL; Andre, GR (1987). Comparative testing of Plasmodium falciparum sporozoite monoclonal antibodies for ELISA development. Bull Wld Hlth Org 65:39-45.

www.fig.net/.../fig2013/.../TS02D_bolaji_abdulhaleem_ oluwafemi_idowu_et_al_669. Accessed 29 June 2017. 